\title{
Immunoglobulin A Nephropathy: Advances in Understanding of Pathogenesis and Treatment
}

\author{
Richard A. Lafayette $^{\mathrm{a}} \quad$ Ellie Kelepouris ${ }^{\mathrm{b}}$ \\ a Division of Nephrology, Department of Medicine, Stanford University, Stanford, CA, USA; ${ }^{b}$ Division of Nephrology, \\ Department of Medicine, Drexel University College of Medicine, Philadelphia, PA, USA
}

\section{Keywords}

Immunoglobulin A nephropathy · Primary

glomerulonephritis - Autoimmune - Genetic predisposition .

Immune complexes · Podocytes · Treatment · New

therapeutic targets · Review

\begin{abstract}
Background: Immunoglobulin A $(\lg A)$ nephropathy is the most common form of primary glomerulonephritis and has clinical associations with a wide range of inflammatory and infectious diseases. There is a substantial variation in clinical course and outcomes, with many patients not diagnosed until they present with sequelae, which may include gross hematuria, hypertension, renal insufficiency, and/or significant proteinuria. Treatment options are currently limited and directed mainly toward control of these sequelae and have limited ability to reduce the incidence of end-stage renal disease or treat the primary lgA defect. Summary: Growing knowledge about the pathogenesis of IgA nephropathy and research into its genetic basis are helping to elucidate the course of this widely variable disease. $\lg \mathrm{A}$ accumulation in the kidneys is thought to be the result of a number of differ-
\end{abstract}

\section{KARGER}

() 2018 S. Karger AG, Basel

E-Mail karger@karger.com

www.karger.com/ajn ent pathways in a "multi-hit" process that includes an initial traumatic trigger (often infection related) and subsequent memory responses that are amplified in those with a genetic predisposition to the disease and lead to an inflammatory response in susceptible individuals. Genome-wide association studies are providing new insights into the genetic variance of this autoimmune disease and are yielding information that may address both its causes and consequences. Key Messages: New treatment approaches are urgently required for the management of patients with IgA nephropathy. Novel interventions based around its inflammatory nature and "multi-hit" pathogenesis are being investigated to potentially limit disease progression. @ $\quad$ 2018 S. Karger AG, Basel

\section{Introduction}

Immunoglobulin A ( $\operatorname{Ig} A)$ nephropathy is the most common form of primary glomerulonephritis, with a global incidence of at least 2.5 per 100,000 per year in adults [1]. Its prevalence varies substantially by geography and geographic origin; it is most common among 
Asians and rare among Africans [2]. IgA nephropathy is diagnosed by biopsy and is characterized by predominant IgA deposition in the glomerular mesangium [3]. It is a chronic disease that demonstrates substantial variation in clinical epidemiology and course, and has clinical associations with a wide range of other inflammatory and infectious diseases [2]. Proteinuria in IgA nephropathy is often mild to moderate and subnephrotic. Patients with severe nephrosis should be assessed to see whether they have coincidental minimal change disease or primary focal segmental glomerulosclerosis (FSGS).

IgA nephropathy may also exist subclinically. In North America, three-quarters of young patients with IgA nephropathy patients first present with macroscopic hematuria during infection [4]. Older patients often present with proteinuria, microscopic hematuria, and/or hypertension [4]. Furthermore, mesangial IgA deposition was a relatively frequent phenomenon among Japanese renal allograft donors (approximately 16\%) [5]. Autopsy findings suggest that as many as $5 \%$ of the global population may carry undetected renal IgA deposits [6], but most of these patients have a benign form of the disease.

Many patients with IgA nephropathy, even those diagnosed at a young age, can have a good outcome without kidney failure, whereas others will progress to renal failure requiring dialysis or transplant. The clinical course of the disease and an individual's prognosis are determined by a variety of factors, ranging from demographics and genetics to pathology and environmental influences $[3,7$, 8]. Treatment options are currently limited and directed toward the sequelae, but investigations into the components of the "multi-hit" process of pathogenesis, described below, are yielding information that may lead to treatment advances that address both the causes and consequences of the disorder.

This review discusses the pathogenesis of IgA nephropathy, the growing body of genetic research surrounding the disorder, and its prognosis and treatments. It is one of a series of articles summarizing presentations and discussions during a roundtable session focused on proteinuria in nephrotic syndrome [9].

\section{Pathogenesis}

IgA accumulation in the kidneys is thought to be the result of a number of different pathways in a "multi-hit" process that is becoming better elucidated as a result of data from combined genome-wide association studies (GWAS; Fig. 1) [7, 10]. Glomerular deposits of IgA tend

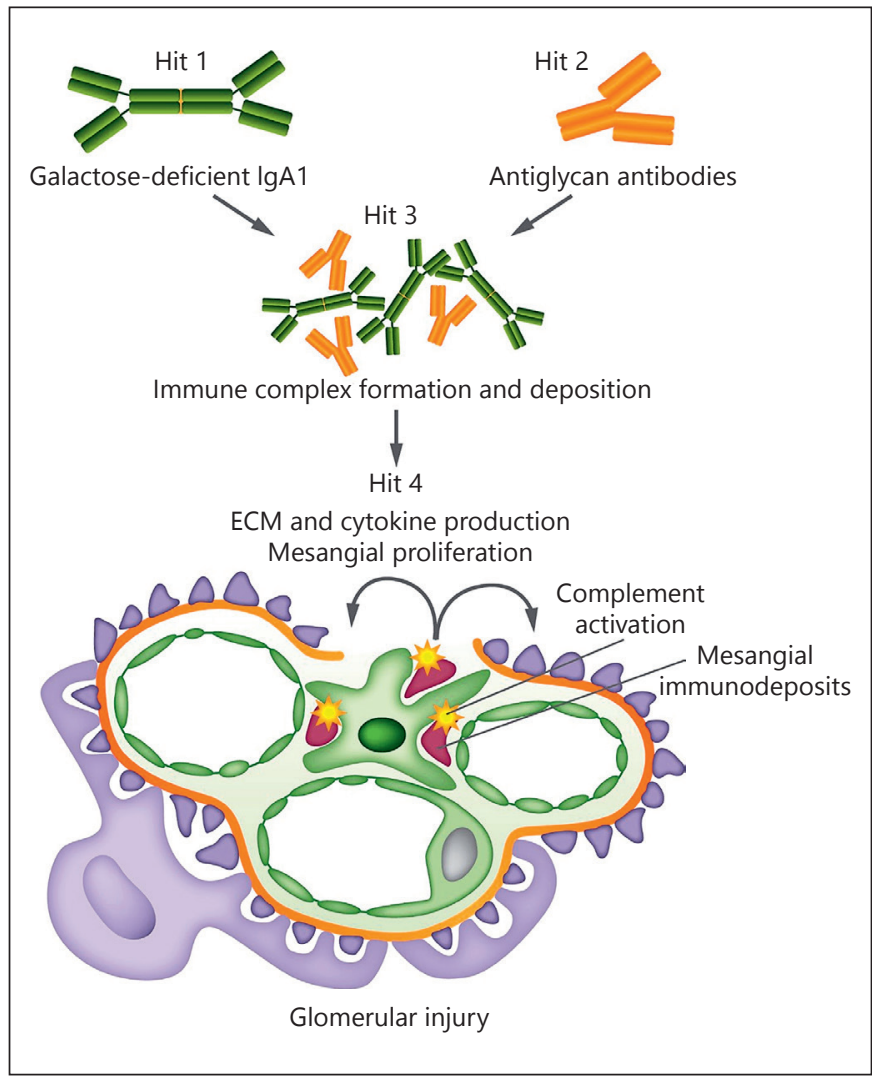

Fig. 1. The "multi-hit" mechanism pathways for the pathogenesis of immunoglobulin A nephropathy [10]. ECM, extracellular matrix; IgA1, immunoglobulin A1. Adapted with permission of Nature Publishing Group, from Magistroni et al. [9]; permission conveyed through Copyright Clearance Center, Inc.

to contain the IgA1 isotype, which is produced largely by plasma cells in the gastrointestinal and respiratory tracts and, to a lesser degree, in the bone marrow and lymph nodes $[11,12]$. The production of IgA 1 by plasma cells is triggered by an initial trauma, such as a mucosal infection (e.g., tonsillitis), stress, or exposure to toxins, followed by a subsequent memory response. Individuals with a genetic predisposition to IgA nephropathy tend to show a higher percentage of galactose-deficient $\mathrm{O}$-glycans in the hinge region of their IgA. High levels of circulating galactose-deficient IgA (Gd-IgA) lead to the formation of antiglycan autoantibodies (both IgA and immunoglobulin G [IgG]), which combine to form pathogenic immune complexes that target the kidneys and are deposited in the mesangium $[7,10]$. Targeting the mesangium is thought to be the result of a lectin-associated mechanism [13].

Interference in mucosal immunity, involving the intestinal network of IgA production, maintenance of the
Lafayette/Kelepouris 
intestinal mucosal barrier, and other defense mechanisms against intracellular pathogens, is thought to be a major contributory factor to IgA nephropathy. Secretory IgA is known to regulate the intestinal microbiome, working to prevent pathogen overgrowth. The production of IgA1 is dysregulated in patients with IgA nephropathy. Patients with inflammatory bowel disease and recurrent intestinal infection are thought to have an altered IgA1 response, and there are also possible links to instances of macroscopic hematuria related to mucosal infections and subsequent changes in local IgA1 response [13]. While dysregulation of mucosal IgA production is thought to be a cause of IgA nephropathy, an alteration in the mucosal innate immunity leading to a dysregulated response to mucosal antigens causes a defect in allorecognition in the major histocompatibility alleles and a cascade of immune complex formation (marked by the presence of antiglycan autoantibodies) that results in deposits within the glomerulus $[10,13]$.

Susceptible individuals experience an inflammatory response to the immune complexes resulting in proliferation of the mesangial cells, expansion of the extracellular matrix, the release of cytokines and growth factors (including transforming growth factor beta 1), and podocyte and tubular injury leading to a slowly progressive deterioration in renal function [3]. A study of functional and morphological covariates of disease severity in patients with IgA nephropathy has shown a link between increased severity of glomerular dysfunction, as measured by glomerular filtration rate (GFR), and reduced levels of glomerular podocytes, and suggests a relationship between increased disease severity in IgA nephropathy and podocyte loss [14]. Patients with IgA nephropathy have also been found to have increased urinary excretion of podocytes $[14,15]$. Although a direct link between mesangial IgA complexes and podocyte damage has yet to be found, immunofluorescence staining indicates that some Gd-IgA deposition may also occur outside the mesangium in the region of the peripheral capillary loop [16], which may provide a mechanism for podocyte and tubular damage. There is also evidence of a nonspecific IgA receptor, which appears to be nonfunctional, present in most human cells, including podocytes [16]. In vitro studies suggest the existence of crosstalk between humoral factors/mediators released from the glomerular mesangial cell/IgA/IgG combination and podocytes, similar to what is thought to be involved in the development of tubulointerstitial damage in IgA nephropathy. These mediators stimulate localized secretion of tumor necrosis factor alpha, leading to an upregulation of interleukin 6 and other pro-inflammatory cytokines that can cause podocyte injury through an indirect mechanism (Fig. 2) $[16,17]$. Changes in the structure and function of podocytes from patients with IgA nephropathy have been confirmed by Gd-IgA mesangial cell co-cultures. These may be related to downregulation of nephrin, leading to a dedifferentiation of podocytes, loss of adhesion molecules, and a move toward apoptosis [17].

Immunofluorescence studies also show a variable amount of complement activation in glomeruli affected by IgA deposits. The presence of high levels of complement component 3 is an indication of a worse prognosis and likelier progression to renal failure $[18,19]$.

\section{Genetic Associations}

New insights suggest that IgA nephropathy is an autoimmune disease with a strong genetic determination. This manifests both in the microbiome and in geographic differences in susceptibility to Gd-IgA.

Genetic variance appears to play a key role in the clinical development of IgA nephropathy. While most healthy individuals appear to carry some level of Gd-IgA in their sera, only a subset of the population appears to be predisposed to clinical disease. Cohort studies in families of patients with both pediatric and adult IgA nephropathy have shown that serum levels of Gd-IgA are not only high in IgA nephropathy patients, but are also raised above normal in blood relatives without the disease compared with non-related controls. In an adult study $(n=89$ cases and 266 relatives), high Gd-IgA1 levels were observed in 5 patients with familial IgA nephropathy, in 21 of 45 (47\%) of their at-risk relatives (suggesting autosomal dominant inheritance), and in only 1 of 19 (5\%) unrelated individuals who married into the family [20]. Among 34 pediatric patients with IgA nephropathy or Henoch-Schönlein purpura nephritis, Gd-IgA1 levels were significantly higher compared with 51 age- and ethnicity-matched controls, as were those of first-degree relatives $(n=53)$ compared with adult controls $(n=141)$ [21]. Gd-IgA1 heritability in the adult study was $54 \%(p=$ $0.0001)$, and that in the pediatric study was $71 \%(p=$ $0.002)[20,21]$.

The level of Gd-IgA1 in the sera of patients with IgA nephropathy is known to be independently associated with disease progression, with cumulative renal survival being lowest in patients with the highest Gd-IgA titers [22]. Kaplan-Meier survival curves, without the dialysis/ death event, showed that patients with higher levels of 


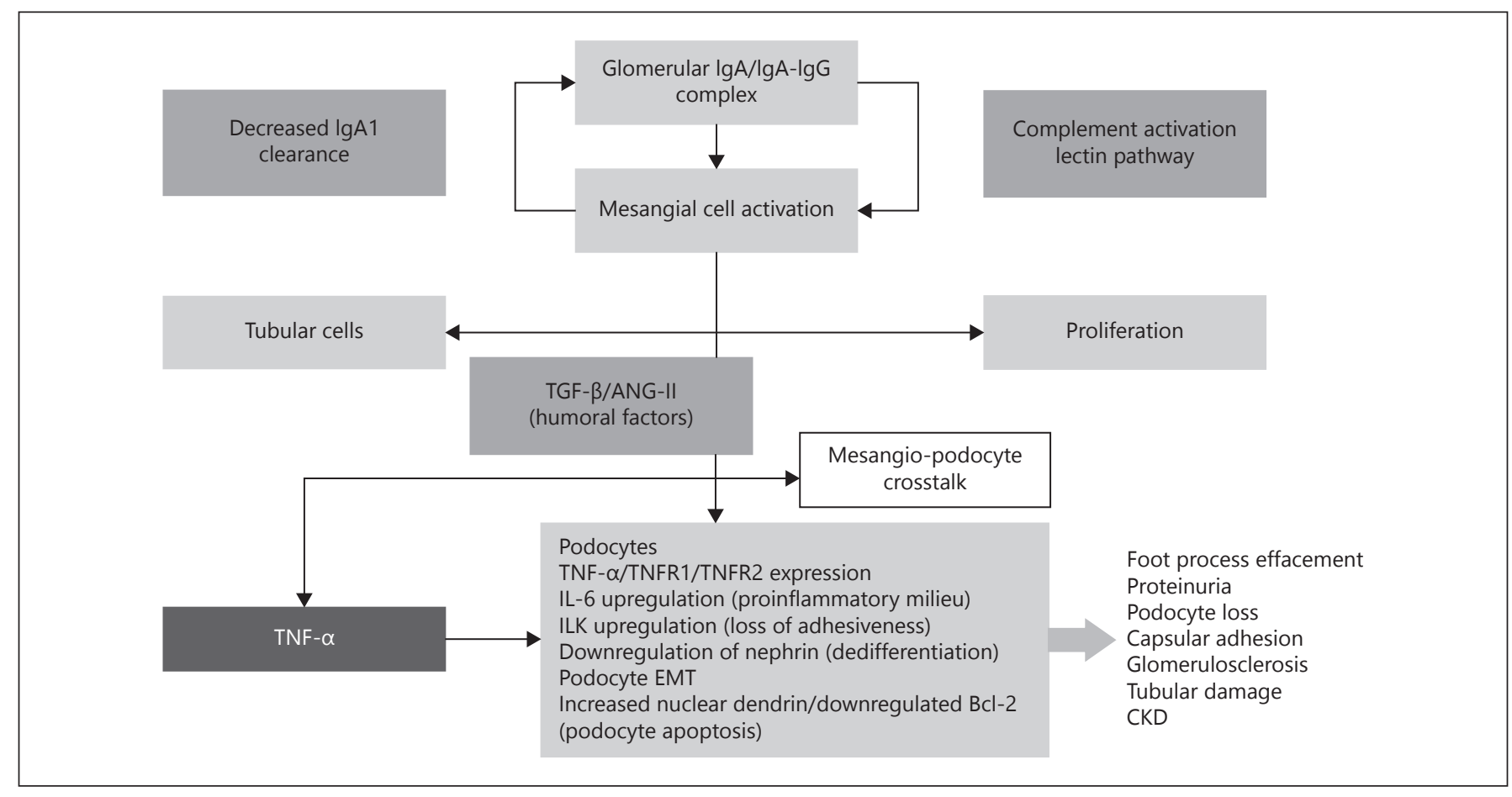

Fig. 2. Mesangial cell activation and mechanism of podocyte injury in immunoglobulin A nephropathy. ANG-II, angiotensin II; Bcl-2, B cell lymphoma 2; CKD, chronic kidney disease; EMT, epithelial-mesenchymal transition; IgA, immunoglobulin A; IgG, immunoglobulin G; IL-6, interleukin 6; ILK, integrin-linked ki- nase; TGF- $\beta$, transforming growth factor beta; TNF- $\alpha$, tumor necrosis factor alpha; TNFR1, tumor necrosis factor receptor 1; TNFR2, tumor necrosis factor receptor 2. Adapted with permission of S. Karger AG, from Menon et al. [16]; permission conveyed through Copyright Clearance Center, Inc. both IgG and IgA autoantibodies to Gd-IgA (IgG $\geq 1.33$ and/or IgA $\geq 1.79$ ) had a worse survival rate of 76 and $56 \%$, respectively, at 5 and 10 years post diagnosis than those with lower levels of autoantibodies (97 and 85\%, respectively; $p=0.004$ ) [23].

IgA nephropathy GWAS have successfully identified 7 independent risk loci with genome-wide significance $(p<$ $5 \times 10^{-8}$ ) [13]. Several genes have been identified in patients with IgA nephropathy that provide insights into the pathways driving its pathogenesis. These include the antigen processing and presentation pathway (loci on chromosome 6 p21 within the major histocompatibility locus; $H L A-D Q B 1 / D R B 1, P S M B 9 / T A P 1$, and DPA1/DPB2), the alternative complement pathway (chromosome $1 \mathrm{q} 32 ; C F H R 3 / R 1$ ), and the mucosal immunity pathway (chromosome 22q12; HORMAD2) [2, 13, 24-27]. These loci are thought to be related to mucosal immunity and alternative-complement pathways and may contribute directly to IgA nephropathy risk [2]. These loci have been found to be associated with other forms of autoimmune and inflammatory disorders, including inflammatory bowel disease and some forms of multiple sclerosis [2]. However, these loci account for the development of $<10 \%$ of cases of IgA nephropathy. Thus, a large proportion of IgA nephropathy risk is unexplained, which suggests that there are additional loci that are yet to be identified.

Susceptibility to IgA nephropathy also varies according to geography and ethnicity, suggesting that both genetics and environment may play a role; common among Asian populations, it is only moderately prevalent in Europeans and is rare in those of African origin [2]. GWAS for IgA nephropathy, involving more than 20,500 individuals of European and Asian ancestry, have helped identify 15 independent risk alleles, from 10 distinctive genomic regions, that are present in Asians and Europeans but are rare in Africans [2]. Although no direct link has been made, it has been postulated that these alleles may be concordant with the variation in disease prevalence among the different populations [2]. Kiryluk et al. [24] also noted that the highest genetic predisposition for IgA nephropathy-associated end-stage renal disease (ESRD) lies in patients from the northern latitudes of 
Europe and also of Asia, and that this reduces along a north-to-south gradient. The high incidence of IgA nephropathy in the Asian subcontinent has been linked to the large number and diversity of soil-transmitted helminthic infections, including schistosomiasis, suggesting a possible role for host-intestinal pathogen interactions influencing the microbiome and triggering an inflammatory cascade [2].

\section{Diagnosis and Prognosis}

Patients with IgA nephropathy are often not diagnosed until they present with evidence of renal disease including gross hematuria, hypertension, renal insufficiency, and significant proteinuria. Depending on patients' other prognostic factors, the clinical course may remain benign with stable kidney function, or patients may develop progressive fibrosis and chronic kidney disease requiring dialysis or renal transplant. Patients diagnosed with IgA nephropathy without hypertension, proteinuria, or renal insufficiency are unlikely to progress to ESRD within 15 years of diagnosis [28]. For patients presenting with clinical signs or symptoms or with proteinuria, the proportion rises to $30-40 \%$, and for patients with renal insufficiency at diagnosis, $50-70 \%$ are expected to progress. A review of long-term follow-up studies globally demonstrates that the risk of progression to ESRD increases from $5-15 \%$ of patients after 5 years from appearance of disease to $20-50 \%$ of patients after 20 years [29]. Proteinuria in IgA nephropathy is often mild to moderate and subnephrotic. Patients with severe nephrosis should be assessed to see if they have coincidental minimal change disease or primary FSGS.

Only a minority of patients with IgA nephropathy are able to achieve clinical remission (both hematuria and proteinuria remission), indicating that the primary pathogenesis may be of extra-renal origin. This correlates with findings in transplant patients showing high levels of recurrence, with about 50\% demonstrating evidence of IgA deposition on renal biopsy up to 10 years post transplantation [30]. Graft failure due to IgA nephropathy appears to be time-dependent: only 1-2\% of allografts are lost to IgA nephropathy in the first decade after transplantation, with graft loss reaching a clinically significant level of $8-10 \%$ only between 10 and 15 years post transplant $[31,32]$.

Clinical indicators of poor prognosis in IgA nephropathy vary by initial presentation and, as discussed above, by geographic and genetic background. Commonly documented indicators have included reduced renal func- tion, severity of proteinuria, and hypertension [33, 34]. A 30 -year retrospective study of a cohort of IgA nephropathy patients with relatively severe disease who presented to a US referral center indicated the most powerful indicators of poor outcomes to be baseline estimated GFR (eGFR) and African-American race [35].

From a histopathological perspective, the clearest indicator of poor prognosis based on the Oxford Classification of IgA Nephropathy $[36,37]$ relates to the poor outcomes associated with more extensive levels of scarring. The presence of a focal sclerosis lesion in patients with IgA nephropathy is known to confer a worse clinical prognosis, even in patients with mild clinical disease [38]. The nature of the link between focal segmental glomerulosclerosis and IgA nephropathy is unclear, but segmental glomerulosclerosis is known to be common in IgA nephropathy, occurring in $76 \%$ of patients from the Oxford classification cohort with proteinuria $>0.5 \mathrm{~g}$ per $24 \mathrm{~h}$ [39]. Three potential mechanisms have been suggested for the segmental glomerulosclerosis found in IgA nephropathy. These include fibrotic activity within segmental necrotizing/proliferative lesions, loss of nephrons, and podocyte injury [40]. Histological evidence of podocyte injury includes podocyte hypertrophy, hyperplasia, hyalinosis, capillary foam cells, protein absorption droplets, and tip lesions [41]. Segmental necrosis has also been seen in association with segmental lesions, providing another link to the hypothesis of podocyte injury [42]. Scarring on biopsies generally confers a worse prognosis, with interstitial fibrosis predicting even poorer outcomes than global or focal glomerulosclerosis [39]. The degree of crescents is also thought to be an indicator of poor prognosis of IgA nephropathy [43] in most, but not all, studies [44, 45]. During the preparation of this paper, Haas et al. [46] published a report of a study of the predictive value of crescents in IgA nephropathy, the results of which led them to propose the addition of the following crescent scores to the Oxford Classification: C0 (no crescents); C1 (crescents in less than one-fourth of glomeruli), identifying patients at increased risk of poor outcome without immunosuppression; and C2 (crescents in over one-fourth of glomeruli), identifying patients at even greater risk of progression, even with immunosuppression. Whether this is due to the more episodic nature of the disease in patients who demonstrate crescents or due to the differences in the timing and nature of their treatment is unclear.

A similar level of uncertainty surrounds the outcomes of patients with gross hematuria [47]. Co-deposition of IgG by immunofluorescence microscopy is also a predictor of progression to ESRD [35]. 
Table 1. Evidence-based treatment options for immunoglobulin A nephropathy [48]

\begin{tabular}{ll}
\hline KDIGO guidance & KDIGO evidence level \\
\hline $\begin{array}{l}\text { Effective } \\
\text { Angiotensin-converting enzyme } \\
\text { inhibitors/angiotensin II } \\
\text { receptor blockers }\end{array}$ & $\begin{array}{l}\text { 1B (Recommended - } \\
\text { moderate) }\end{array}$ \\
$\begin{array}{ll}\text { Corticosteroids } \\
\text { Uncertain }\end{array}$ & 2C (Suggested - low) \\
$\begin{array}{l}\text { Fish oils } \\
\text { Cyclophosphamide }\end{array}$ & 2D (Suggested - very low) \\
\hline $\begin{array}{l}\text { Ineffective (not to be used) } \\
\text { Azathioprine and mycophenolate } \\
\quad \text { mofetil }\end{array}$ & 2C (Suggested - low) \\
$\begin{array}{l}\text { Tonsillectomy } \\
\text { Antiplatelet agents }\end{array}$ & 2C (Suggested - low) \\
\hline
\end{tabular}

\section{Treatment Options}

Currently, effective treatment options for IgA nephropathy are limited and focus on conservative measures to arrest disease progression rather than treating the primary IgA defect. None of these has yet been studied in large-scale clinical trials, and the evidence for their benefit is limited to small trials and observations (Table 1) [48].

In the Kidney Disease: Improving Global Outcomes (KDIGO) consensus treatment guidelines, the option with the most convincing benefit is antihypertensive control using renin-angiotensin system (RAS) inhibitors (angiotensin-converting enzyme inhibitors [ACEIs] or angiotensin II receptor blockers [ARBs]). While these have been shown to reduce proteinuria and improve kidney function, they have not been documented to reduce the incidence of ESRD. There is no evidence to differentiate the effectiveness of ACEIs versus ARBs, although a better side-effect profile has been reported with ARBs [48]. Dual blockade using combined RAS inhibitors with different pathways of action (e.g., ACEIs plus an ARB or direct renin inhibitor) has been investigated with promising effects, but more evidence is required to assess benefits and ensure they overcome the risks of this approach [48].

Immunosuppression using corticosteroids, azathioprine, cyclophosphamide, or mycophenolate mofetil in order to dampen the IgA1 inflammatory effect or to lower IgA1 production by killing plasma or B cells, has been tried for a number of years with mixed results. While some encouraging response rates in reducing proteinuria and delaying renal damage have been seen, the results from ran- domized controlled trials, other than those with singleagent corticosteroids, have been variable. The most promising results have been obtained in studies with either a 6-month course of steroid treatment (intravenous methylprednisolone $1 \mathrm{~g}$ per day for 3 consecutive days at the beginning of months 1,3 , and 5 , plus oral prednisone $0.5 \mathrm{mg} / \mathrm{kg}$ on alternate days for 6 months) [49] or with oral prednisone $(0.8-1.0 \mathrm{mg} / \mathrm{kg}$ per day) plus ramipril for 2 months, weaned over 6 months [50]. The protocols used in these studies both induced reduction in disease progression and proteinuria without serious side effects. The KDIGO guidelines do not recommend the use of immunosuppressive agents but suggest that patients with persistent proteinuria $\geq 1 \mathrm{~g} /$ day, despite 3-6 months of optimized supportive care (including ACEIs or ARBs and blood pressure control), and GFR $>50 \mathrm{~mL} / \mathrm{min}$ per $1.73 \mathrm{~m}^{2}$, receive a 6-month course of corticosteroid therapy [48].

Fish oil supplements have been suggested as a low-risk additional option, especially in patients with persistent proteinuria despite 3-6 months of supportive care, because of their potentially beneficial antihypertensive and cardiovascular benefits but, again, results have been mixed [48]. Lifestyle modification, including dietary intervention involving a low-salt diet, is also a general recommendation for hypertension control [48].

Tonsillectomy has been suggested as a surgical option to reduce the number of IgA1-producing sites and to limit the high circulating levels of IgA1 in patients with IgA nephropathy. However, the approach is not universal and it has not been employed routinely worldwide. In the rationale for their trial, Kawamura et al. [51] note that although its use in Japan is reasonably common, some studies suggest benefit, while others do not. The results of their relatively small, randomized, clinical trial indicated that tonsillectomy combined with steroid pulse therapy did not increase the incidence of clinical remission or reduce hematuria compared with steroid pulses alone.

As tonsillectomy poses a risk in adults, in the absence of well-powered randomized controlled trials, the KDIGO guidelines do not recommend its use [48]. Further randomized clinical trials and long-term follow-up are required to clarify the position.

\section{Recent and Ongoing Studies}

Continued investigations into immunosuppressive regimens and other therapeutic options are underway or have recently reported results. In a prospective, openlabel, parallel-group, randomized controlled trial con- 
ducted in Germany (STOP-IgAN study; NCT00554502), patients $(n=337)$ underwent a 6 -month run-in phase with supportive care to reduce proteinuria and decrease blood pressure. Those with persistent proteinuria (between 0.75 and $3.5 \mathrm{~g}$ per day) were randomized either to receive supportive care alone or to continue supportive care and add immunosuppressive therapy (methylprednisolone and oral prednisolone regimen or cyclophosphamide followed by azathioprine and oral prednisolone) for the 3-year study phase. The addition of immunosuppressive therapy was superior to supportive care alone in inducing full remission of proteinuria but not in decreasing the rate of decline in eGFR (co-primary endpoints) [52]. Patients in the immunosuppression group also showed more side effects, leaving doubts over the value of immunosuppressive therapy in $\operatorname{IgA}$ nephropathy. It is worth noting that of the 309 patients who completed the 6-month supportive care run-in phase, 106 responded to supportive care (proteinuria level, $<0.75 \mathrm{~g}$ of urinary protein excretion per day after the end of the run-in phase) and were not eligible for randomization.

Results from a randomized controlled trial of rituximab in IgA nephropathy looking at the effects of depleting antibody-producing B cells were recently presented [53]. The study was a multicenter trial of 34 adult patients with biopsy-proven $\operatorname{IgA}$ nephropathy and proteinuria $>1$ g per day, maintained on ACEIs or ARBs with well-controlled blood pressure and eGFR $<90 \mathrm{~mL} / \mathrm{min} / 1.73 \mathrm{~m}^{2}$, randomized to receive supportive therapy either alone or with rituximab. Addition of rituximab did not alter the level of proteinuria compared with that at baseline or in the control group, and did not alter eGFR (primary outcome measures). Rituximab did effectively deplete B cells, but failed to reduce serum levels of Gd-IgA1 or autoantibodies over a 1-year follow-up period.

The NEFIGAN study (NCT01738035) was a randomized multicenter trial comparing oral budesonide modified-release capsules with placebo in patients $(n=150)$ with IgA nephropathy who, after a 6-month run-in phase targeting blood pressure control with ACEIs or ARBs, have urine protein:creatinine ratio $\geq 0.5 \mathrm{~g} / \mathrm{g}$ or urine protein $\geq 0.75 \mathrm{~g}$ per $24 \mathrm{~h}$ and GFR $\geq 45 \mathrm{~mL} / \mathrm{min} / 1.73 \mathrm{~m}^{2}$. Planned interim analysis was positive for the primary outcome of mean reduction in urine protein:creatinine ratio during the 9-month treatment period compared with placebo $(p<0.01)$ [54].

The TESTING study (NCT01560052), conducted mainly in Asia, is a large, ongoing, randomized controlled trial comparing oral methylprednisolone with placebo in patients with IgA nephropathy. Planned enrollment was approximately 1,300 patients, followed for 1-6 years, with a projected completion date in 2022 [55]. Despite an initially promising result, the TESTING trial was halted by the data safety monitoring committee because of a disproportionately high number of infection complications within the methylprednisolone arm. The recent publication of this trial concluded that, although the results were consistent with potential renal benefit, definitive conclusions about treatment benefit could not be made due to the early termination of the trial [56]. A lower dose interventional study with antimicrobial prophylaxis is underway.

The clinical effect of atacicept, a recombinant fusion protein that blocks both $\mathrm{B}$ cell-activating factor and a proliferation-inducing ligand (APRIL), is being investigated for treating systemic autoimmune diseases [57]. Studies will investigate the contribution of dysregulation of IgA 1 secretion in the intestinal epithelium to see if intestinal immunity or mucosal immunity inhibitors of overexpression of APRIL and B cell-activating factor can have a clinical effect. A phase II clinical trial (NCT02808429) investigating the efficacy of atacicept in patients with $>1,000$ $\mathrm{mg}$ of proteinuria per $24 \mathrm{~h}$ is currently enrolling.

The role of adrenocorticotropic hormone has also been considered in the treatment of resistant glomerular diseases. Potential mechanisms include stimulation of endogenous steroid production, activation of melanocortin receptors on inflammatory cells, and direct binding to melanocortin receptors on the podocyte [58]. Administration of a 6-month course of adrenocorticotropic hormone gel in patients with IgA nephropathy at high risk of progression (proteinuria $>1,000 \mathrm{mg}$ per $24 \mathrm{~h}$ despite documented ACEI/ARB therapy and adequate blood pressure control for $>3$ months; $24-\mathrm{h}$ creatinine clearance $>30 \mathrm{~mL} / \mathrm{min} / 1.73 \mathrm{~m}^{2}$ ) is being prospectively investigated in an open-label pilot study (NCT02282930). Data on the primary outcome of complete or partial response at 12 months are anticipated in June/July 2018.

\section{Newer Therapeutic Targets}

IgA nephropathy is an inflammatory disease with an initial acceleration of the inflammatory process cascade followed by resolution of inflammation. It would seem that interventions at the acceleration phase, when there is significant proteinuria but before scarring and ESRD have occurred, are likely to be the most effective and to 
offer the possibility of altering the natural progression of the disease. There is growing research to show that chronic inflammatory diseases, such as rheumatoid arthritis, systemic lupus erythematosus, multiple sclerosis, and inflammatory conditions of the retina, are often associated with dysregulated immune responses.

Possible interventions around the acceleration phase include looking at ways to deplete IgA and autoantibodies, either in their circulating state or by downregulating or removing plasma cells while limiting the effect on mucosal immunity. The melanocortin receptor pathway is one example of a process that can be regulated to decrease the inflammation in these conditions [59] and, as this pathway is also well developed in the kidney, it offers a potential target in proteinuric nephropathies, including IgA nephropathy. In addition, as immunosuppressive agents are being investigated for their general immunomodulatory effects, it is noteworthy that they may also have potential direct effects at receptors in the podocyte. Podocyte-specific targets may provide an additional avenue for exploration by potentially limiting the damage caused by IgA1 immune complex deposition in the renal mesangium. Furthermore, our understanding has increased regarding the role of complement activation in IgA nephropathy and the potential role of complement inhibitors [60,61]. A recent review by Maillard et al. [19] highlights the growing body of evidence that suggests involvement of the complement pathway as a key event in the pathogenesis of IgA nephropathy, and it is clear that activation of complement plays a role in the clinical expression of the disease. The authors suggest that the process occurs both systemically on IgAcontaining circulating immune complexes, and also locally in glomeruli, and is mediated through both the alternative and lectin pathways. Both of these pathways can be activated by IgA1 in vitro. Furthermore, pathway components are present in the mesangial immunodeposits, including properdin and factor $\mathrm{H}$ (alternative pathway) and mannan-binding lectin, mannan-binding lectin-associated serine proteases 1 and 2, and C4d (lectin pathway). Deletion of complement factor $\mathrm{H}$-related genes 1 and 3 has been identified as protective against the disease in GWAS. Complement involvement may pave the way for new treatment options that target complement activation (such as the recently available anti$\mathrm{C} 5$ and anti-C5aR antibodies) and novel biomarkers (activation of C3). These new approaches may represent promising options for the management of some patients with IgA nephropathy.

\section{Conclusions}

IgA nephropathy is a widespread progressive primary glomerulonephritic disease with limited treatment options for which new treatment approaches are urgently required. Potential new interventions based around IgA nephropathy's inflammatory nature and "multi-hit" pathogenesis are being investigated in the hope of being able to limit disease progression.

\section{Acknowledgments}

This article is based on discussions at a roundtable meeting supported by a grant from Mallinckrodt Pharmaceuticals. Presentations and discussions were developed solely by the participants, without grantor input. The meeting chair, James Tumlin, determined the agenda and attendees. R.A.L. and E.K. developed the presentations and led the discussions upon which this article is based, provided critical review and revisions to the outline and manuscript drafts, provided final approval of the version to be published, and are accountable for the integrity of the content and for addressing questions. The authors gratefully acknowledge the contributions of the following individuals who participated in the discussion that shaped the content of this article: Andrew Bomback, Kirk Campbell, Fernando Fervenza, Puneet Garg, and James Tumlin. Writing and editorial assistance were provided by Louise Alder, Sharon Suntag, and Susan Andrews of IQVIA.

\section{Disclosure Statement}

R.A.L. and E.K. received honoraria from IQVIA (formerly QuintilesIMS) for their participation in a roundtable meeting supported by a grant from Mallinckrodt Pharmaceuticals. E.K. is the recipient of grant funding from Mallinckrodt Pharmaceuticals and serves on their Medical Advisory Board.

\section{References}

1 McGrogan A, Franssen CF, de Vries CS: The incidence of primary glomerulonephritis worldwide: a systematic review of the literature. Nephrol Dial Transplant 2011;26:414430.

2 Kiryluk K, Li Y, Scolari F, Sanna-Cherchi S, Choi M, Verbitsky M, Fasel D, Lata S, Prakash S, Shapiro S, Fischman C, Snyder HJ, Appel G, Izzi C, Viola BF, Dallera N, Del Vecchio L, Barlassina C, Salvi E, Bertinetto FE, Amoroso A, Savoldi S, Rocchietti M, Amore A, Peruzzi L, Coppo R, Salvadori M, Ravani P, Magistroni R, Ghiggeri GM, Caridi G, Bodria M, Lugani F, Allegri L, Delsante M, Maiorana M, Magnano A, Frasca G, Boer E, Boscutti G, Ponticelli C, Mignani R, Marcantoni C, Di Landro D, Santoro D, Pani A, Polci R, Feriozzi S, Chicca S, Galliani M, Gigante M, Gesualdo L, Zamboli P, Battaglia GG, Garozzo M,
Lafayette/Kelepouris 
Maixnerova D, Tesar V, Eitner F, Rauen T, Floege J, Kovacs T, Nagy J, Mucha K, Paczek L, Zaniew M, Mizerska-Wasiak M, Roszkowska-Blaim M, Pawlaczyk K, Gale D, Barratt J, Thibaudin L, Berthoux F, Canaud G, Boland A, Metzger M, Panzer U, Suzuki H, Goto S, Narita I, Caliskan Y, Xie J, Hou P, Chen N, Zhang H, Wyatt RJ, Novak J, Julian BA, Feehally J, Stengel B, Cusi D, Lifton RP, Gharavi AG: Discovery of new risk loci for IgA nephropathy implicates genes involved in immunity against intestinal pathogens. Nat Genet 2014;46:1187-1196.

3 Lafayette RA: Immunoglobulin A nephropathy: insights and progress. Transl Res 2014; 163:3-7.

4 Wyatt RJ, Julian BA: IgA nephropathy. N Engl J Med 2013;368:2402-2414.

5 Suzuki K, Honda K, Tanabe K, Toma H, Nihei $\mathrm{H}$, Yamaguchi $\mathrm{Y}$ : Incidence of latent mesangial IgA deposition in renal allograft donors in Japan. Kidney Int 2003;63:2286-2294.

6 Waldherr R, Rambausek M, Duncker WD, Ritz E: Frequency of mesangial IgA deposits in a non-selected autopsy series. Nephrol Dial Transplant 1989;4:943-946.

7 Suzuki H, Kiryluk K, Novak J, Moldoveanu Z, Herr AB, Renfrow MB, Wyatt RJ, Scolari F, Mestecky J, Gharavi AG, Julian BA: The pathophysiology of IgA nephropathy. J Am Soc Nephrol 2011;22:1795-1803.

8 D'Amico G: Natural history of idiopathic IgA nephropathy and factors predictive of disease outcome. Semin Nephrol 2004;24: 179-196.

9 Tumlin JA, Campbell KN: Proteinuria in nephrotic syndrome: mechanistic and clinical considerations in optimizing management. Am J Nephrol 2018;47(suppl 1):1-2.

10 Magistroni R, D’Agati VD, Appel GB, Kiryluk $\mathrm{K}$ : New developments in the genetics, pathogenesis, and therapy of IgA nephropathy. Kidney Int 2015;88:974-989.

11 Kato A, Hulse KE, Tan BK, Schleimer RP: Blymphocyte lineage cells and the respiratory system. J Allergy Clin Immun 2013;131:933957; quiz 958

12 Kett K, Brandtzaeg P, Radl J, Haaijman JJ: Different subclass distribution of IgA-producing cells in human lymphoid organs and various secretory tissues. J Immunol 1986;136:36313635.

13 Kiryluk K, Novak J: The genetics and immunobiology of IgA nephropathy. J Clin Invest 2014;124:2325-2332.

14 Lemley KV, Lafayette RA, Safai M, Derby G, Blouch K, Squarer A, Myers BD: Podocytopenia and disease severity in IgA nephropathy. Kidney Int 2002;61:1475-1485.

15 Hara M, Yamamoto T, Yanagihara T, Takada T, Itoh M, Adachi Y, Yoshizumi A, Kawasaki K, Kihara I: Urinary excretion of podocalyxin indicates glomerular epithelial cell injuries in glomerulonephritis. Nephron 1995;69:397403.

16 Lai KN, Leung JC, Chan LY, Saleem MA, Mathieson PW, Lai FM, Tang SC: Activation of podocytes by mesangial-derived TNF-alpha: glomerulo-podocytic communication in IgA nephropathy. Am J Physiol Renal Physiol 2008;294:F945-F955.

17 Menon MC, Chuang PY, He JC: Role of podocyte injury in $\operatorname{IgA}$ nephropathy. Contrib Nephrol 2013;181:41-51.

18 Kim SJ, Koo HM, Lim BJ, Oh HJ, Yoo DE, Shin DH, Lee MJ, Doh FM, Park JT, Yoo TH, Kang SW, Choi KH, Jeong HJ, Han SH: Decreased circulating C3 levels and mesangial C3 deposition predict renal outcome in patients with IgA nephropathy. PLoS One 2012; 7:e40495.

19 Maillard N, Wyatt RJ, Julian BA, Kiryluk K, Gharavi A, Fremeaux-Bacchi V, Novak J: Current understanding of the role of complement in IgA nephropathy. J Am Soc Nephrol 2015;26:1503-1512.

20 Gharavi AG, Moldoveanu Z, Wyatt RJ, Barker CV, Woodford SY, Lifton RP, Mestecky J, Novak J, Julian BA: Aberrant IgA1 glycosylation is inherited in familial and sporadic IgA nephropathy. J Am Soc Nephrol 2008;19: 1008-1014.

21 Kiryluk K, Moldoveanu Z, Sanders JT, Eison TM, Suzuki H, Julian BA, Novak J, Gharavi AG, Wyatt RJ: Aberrant glycosylation of IgA1 is inherited in both pediatric IgA nephropathy and Henoch-Schönlein purpura nephritis. Kidney Int 2011;80:79-87.

22 Zhao N, Hou P, Lv J, Moldoveanu Z, Li Y, Kiryluk K, Gharavi AG, Novak J, Zhang H: The level of galactose-deficient IgA1 in the sera of patients with IgA nephropathy is associated with disease progression. Kidney Int 2012;82:790-796.

23 Berthoux F, Suzuki H, Thibaudin L, Yanagawa H, Maillard N, Mariat C, Tomino Y, Julian BA, Novak J: Autoantibodies targeting galactose-deficient IgA1 associate with progression of IgA nephropathy. J Am Soc Nephrol 2012;23:1579-1587.

24 Kiryluk K, Li Y, Sanna-Cherchi S, Rohanizadegan M, Suzuki H, Eitner F, Snyder HJ, Choi M, Hou P, Scolari F, Izzi C, Gigante M, Gesualdo L, Savoldi S, Amoroso A, Cusi D, Zamboli P, Julian BA, Novak J, Wyatt RJ, Mucha K, Perola M, Kristiansson K, Viktorin A, Magnusson PK, Thorleifsson G, Thorsteinsdottir U, Stefansson K, Boland A, Metzger M, Thibaudin L, Wanner C, Jager KJ, Goto S, Maixnerova D, Karnib HH, Nagy J, Panzer U, Xie J, Chen N, Tesar V, Narita I, Berthoux F, Floege J, Stengel B, Zhang H, Lifton RP, Gharavi AG: Geographic differences in genetic susceptibility to IgA nephropathy: GWAS replication study and geospatial risk analysis. PLoS Genet 2012; 8:e1002765.

25 Gharavi AG, Kiryluk K, Choi M, Li Y, Hou P, Xie J, Sanna-Cherchi S, Men CJ, Julian BA, Wyatt RJ, Novak J, He JC, Wang H, Lv J, Zhu L, Wang W, Wang Z, Yasuno K, Gunel M, Mane S, Umlauf S, Tikhonova I, Beerman I, Savoldi S, Magistroni R, Ghiggeri GM, Bodria M, Lugani F, Ravani P, Ponticelli C, Al- legri L, Boscutti G, Frasca G, Amore A, Peruzzi L, Coppo R, Izzi C, Viola BF, Prati E, Salvadori M, Mignani R, Gesualdo L, Bertinetto F, Mesiano P, Amoroso A, Scolari F, Chen N, Zhang H, Lifton RP: Genome-wide association study identifies susceptibility loci for IgA nephropathy. Nat Genet 2011; 43:321-327.

26 Yu XQ, Li M, Zhang H, Low HQ, Wei X, Wang JQ, Sun LD, Sim KS, Li Y, Foo JN, Wang W, Li ZJ, Yin XY, Tang XQ, Fan L, Chen J, Li RS, Wan JX, Liu ZS, Lou TQ, Zhu L, Huang XJ, Zhang XJ, Liu ZH, Liu JJ: A genome-wide association study in Han Chinese identifies multiple susceptibility loci for IgA nephropathy. Nat Genet 2011;44:178182.

27 Feehally J, Farrall M, Boland A, Gale DP, Gut I, Heath S, Kumar A, Peden JF, Maxwell PH, Morris DL, Padmanabhan S, Vyse TJ, Zawadzka A, Rees AJ, Lathrop M, Ratcliffe PJ: HLA has strongest association with IgA nephropathy in genome-wide analysis. J Am Soc Nephrol 2010;21:1791-1797.

28 Higa A, Shima Y, Hama T, Sato M, Mukaiyama $H$, Togawa H, Tanaka R, Nozu K, Sako M, Iijima K, Nakanishi K, Yoshikawa N: Long-term outcome of childhood IgA nephropathy with minimal proteinuria. Pediatr Nephrol 2015;30:2121-2127.

29 Schena FP: A retrospective analysis of the natural history of primary IgA nephropathy worldwide. Am J Med 1990;89:209215.

30 Cosio FG, Cattran DC: Recent advances in our understanding of recurrent primary glomerulonephritis after kidney transplantation. Kidney Int 2017;91:304-314.

31 Briganti EM, Russ GR, McNeil JJ, Atkins RC, Chadban SJ: Risk of renal allograft loss from recurrent glomerulonephritis. N Engl J Med 2002;347:103-109.

32 Moroni G, Longhi S, Quaglini S, Gallelli B, Banfi G, Montagnino G, Messa P: The longterm outcome of renal transplantation of IgA nephropathy and the impact of recurrence on graft survival. Nephrol Dial Transplant 2013; 28:1305-1314.

33 D'Amico G: Influence of clinical and histological features on actuarial renal survival in adult patients with idiopathic IgA nephropathy, membranous nephropathy, and membranoproliferative glomerulonephritis: survey of the recent literature. Am J Kidney Dis 1992;20:315-323.

34 Le W, Liang S, Hu Y, Deng K, Bao H, Zeng C, Liu $Z$ : Long-term renal survival and related risk factors in patients with IgA nephropathy: results from a cohort of 1155 cases in a Chinese adult population. Nephrol Dial Transplant 2012;27:1479-1485.

35 Arroyo AH, Bomback AS, Butler B, Radhakrishnan J, Herlitz L, Stokes MB, D'Agati V, Markowitz GS, Appel GB, Canetta PA: Predictors of outcome for severe IgA nephropathy in a multi-ethnic U.S. cohort. Clin Nephrol 2015;84:145-155. 
36 Cattran DC, Coppo R, Cook HT, Feehally J, Roberts IS, Troyanov S, Alpers CE, Amore A, Barratt J, Berthoux F, Bonsib S, Bruijn JA, D'Agati V, D'Amico G, Emancipator S, Emma F, Ferrario F, Fervenza FC, Florquin S, Fogo A, Geddes CC, Groene HJ, Haas M, Herzenberg AM, Hill PA, Hogg RJ, Hsu SI, Jennette JC, Joh K, Julian BA, Kawamura T, Lai FM, Leung CB, Li LS, Li PK, Liu ZH, Mackinnon B, Mezzano S, Schena FP, Tomino Y, Walker PD, Wang H, Weening JJ, Yoshikawa $\mathrm{N}$, Zhang $\mathrm{H}$ : The Oxford classification of IgA nephropathy: rationale, clinicopathological correlations, and classification. Kidney Int 2009; 76:534-545.

37 Roberts IS, Cook HT, Troyanov S, Alpers CE, Amore A, Barratt J, Berthoux F, Bonsib S, Bruijn JA, Cattran DC, Coppo R, D'Agati V, D'Amico G, Emancipator S, Emma F, Feehally J, Ferrario F, Fervenza FC, Florquin S, Fogo A, Geddes CC, Groene HJ, Haas M, Herzenberg AM, Hill PA, Hogg RJ, Hsu SI, Jennette JC, Joh K, Julian BA, Kawamura T, Lai FM, Li LS, Li PK, Liu ZH, Mackinnon B, Mezzano S, Schena FP, Tomino Y, Walker PD, Wang H, Weening JJ, Yoshikawa N, Zhang H: The Oxford classification of IgA nephropathy: pathology definitions, correlations, and reproducibility. Kidney Int 2009;76:546-556.

38 Weber CL, Rose CL, Magil AB: Focal segmental glomerulosclerosis in mild IgA nephropathy: a clinical-pathologic study. Nephrol Dial Transplant 2009;24:483-488.

39 El Karoui K, Hill GS, Karras A, Moulonguet L, Caudwell V, Loupy A, Bruneval P, Jacquot C, Nochy D: Focal segmental glomerulosclerosis plays a major role in the progression of IgA nephropathy. II. Light microscopic and clinical studies. Kidney Int 2011;79:643-654.

40 Cook HT: Focal segmental glomerulosclerosis in IgA nephropathy: a result of primary podocyte injury? Kidney Int 2011;79:581583.

41 Bellur SS, Lepeytre F, Vorobyeva O, Troyanov S, Cook HT, Roberts IS: Evidence from the Oxford classification cohort supports the clinical value of subclassification of focal segmental glomerulosclerosis in IgA nephropathy. Kidney Int 2017;91:235-243.

42 Mubarak M, Nasri H: Significance of segmental glomerulosclerosis in IgA nephropathy: What is the evidence? J Renal Inj Prev 2013;2: 113-115.
43 Coppo R, D'Amico G: Factors predicting progression of IgA nephropathies. J Nephrol 2005; 18:503-512.

44 Tomiyoshi Y, Sakemi T, Ikeda Y, Ohtsuka Y, Nakamura M, Fujisaki T: Cellular crescents and segmental glomerular necrosis in IgA nephropathy are indicative of the beneficial effects of corticosteroid therapy. Intern Med 2001;40:862-866.

45 Roberts IS: Pathology of IgA nephropathy. Nat Rev Nephrol 2014;10:445-454.

46 Haas M, Verhave JC, Liu ZH, Alpers CE, Barratt J, Becker JU, Cattran D, Cook HT, Coppo R, Feehally J, Pani A, Perkowska-Ptasinska A, Roberts IS, Soares MF, Trimarchi H, Wang S, Yuzawa Y, Zhang H, Troyanov S, Katafuchi R: A multicenter study of the predictive value of crescents in IgA nephropathy. J Am Soc Nephrol 2017;28:691-701.

47 Le W, Liang S, Chen H, Wang S, Zhang W, Wang X, Wang J, Zeng CH, Liu ZH: Longterm outcome of IgA nephropathy patients with recurrent macroscopic hematuria. Am J Nephrol 2014;40:43-50.

48 Kidney Disease: Improving Global Outcomes (KDIGO) Glomerulonephritis Work Group: KDIGO clinical practice guideline for glomerulonephritis. Kidney Int Suppl 2012;2:139-274.

49 Pozzi C, Bolasco PG, Fogazzi GB, Andrulli S, Altieri P, Ponticelli C, Locatelli F: Corticosteroids in IgA nephropathy: a randomised controlled trial. Lancet 1999;353:883-887.

50 Manno C, Torres DD, Rossini M, Pesce F, Schena FP: Randomized controlled clinical trial of corticosteroids plus ACE-inhibitors with long-term follow-up in proteinuric IgA nephropathy. Nephrol Dial Transplant 2009; 24:3694-3701.

51 Kawamura T, Yoshimura M, Miyazaki Y, Okamoto H, Kimura K, Hirano K, Matsushima M, Utsunomiya Y, Ogura M, Yokoo T, Okonogi $\mathrm{H}$, Ishii $\mathrm{T}$, Hamaguchi A, Ueda $\mathrm{H}$, Furusu A, Horikoshi S, Suzuki Y, Shibata T, Yasuda T, Shirai S, Imasawa T, Kanozawa K, Wada A, Yamaji I, Miura N, Imai H, Kasai K, Soma J, Fujimoto S, Matsuo S, Tomino Y: A multicenter randomized controlled trial of tonsillectomy combined with steroid pulse therapy in patients with immunoglobulin A nephropathy. Nephrol Dial Transplant 2014; 29:1546-1553.

52 Rauen T, Eitner F, Fitzner C, Sommerer C, Zeier M, Otte B, Panzer U, Peters H, Benck U,
Mertens PR, Kuhlmann U, Witzke O, Gross O, Vielhauer V, Mann JF, Hilgers RD, Floege $\mathrm{J}$ : Intensive supportive care plus immunosuppression in IgA nephropathy. N Engl J Med 2015;373:2225-2236.

53 Lafayette RA, Canetta PA, Rovin BH, Appel GB, Novak J, Nath KA, Sethi S, Tumlin JA, Mehta K, Hogan M, Erickson S, Julian BA, Leung N, Enders FT, Brown R, Knoppova B, Hall S, Fervenza FC: A randomized, controlled trial of rituximab in IgA nephropathy with proteinuria and renal dysfunction. J Am Soc Nephrol 2017;28:1306-1313.

54 Fellstrom BC, Barratt J, Cook H, Coppo R, Feehally J, de Fijter JW, Floege J, Hetzel G, Jardine AG, Locatelli F, Maes BD, Mercer A, Ortiz F, Praga M, Sørensen SS, Tesar V, Del Vecchio L: Targeted-release budesonide versus placebo in patients with IgA nephropathy (NEFIGAN): a double-blind, randomised, placebo-controlled phase $2 \mathrm{~b}$ trial. Lancet 2017;389:2117-2127.

55 Lv J, Xu D, Perkovic V, Ma X, Johnson DW, Woodward M, Levin A, Zhang H, Wang H: Corticosteroid therapy in IgA nephropathy. J Am Soc Nephrol 2012;23:1108-1116.

56 Lv J, Zhang H, Wong MG, Jardine MJ, Hladunewich $\mathrm{M}$, Jha V, Monaghan $\mathrm{H}$, Zhao $\mathrm{M}$, Barbour S, Reich H, Cattran D, Glassock R, Levin A, Wheeler D, Woodward M, Billot L, Chan TM, Liu ZH, Johnson DW, Cass A, Feehally J, Floege J, Remuzzi G, Wu Y, Agarwal R, Wang HY, Perkovic V: Effect of oral methylprednisolone on clinical outcomes in patients with IgA nephropathy: the TESTING randomized clinical trial. JAMA 2017;318:432-442.

57 Nakayamada S, Tanaka Y: BAFF- and APRILtargeted therapy in systemic autoimmune diseases. Inflamm Regen 2016;36:1-6.

58 Bomback AS, Canetta PA, Beck LH Jr, Ayalon R, Radhakrishnan J, Appel GB: Treatment of resistant glomerular diseases with adrenocorticotropic hormone gel: a prospective trial. Am J Nephrol 2012;36:58-67.

59 Ahmed TJ, Montero-Melendez T, Perretti M, Pitzalis C: Curbing inflammation through endogenous pathways: focus on melanocortin peptides. Int J Inflam 2013;2013:985815.

60 Daha MR, van Kooten C: Role of complement in IgA nephropathy. J Nephrol 2016;29:1-4.

61 Block G, Whitaker S: The effect of OMS721 on proteinuria in patients with IgA nephropathy. Nephrol Dial Transplant 2017;32:SP113. 